University of Rhode Island

DigitalCommons@URI

Open Access Master's Theses

2020

\title{
THE ROLE OF SELF-EFFICACY IN THE RELATIONSHIP BETWEEN CHILDHOOD TRAUMA AND ANXIETY
}

Elaine Green

University of Rhode Island, elainegreen@uri.edu

Follow this and additional works at: https://digitalcommons.uri.edu/theses

\section{Recommended Citation}

Green, Elaine, "THE ROLE OF SELF-EFFICACY IN THE RELATIONSHIP BETWEEN CHILDHOOD TRAUMA AND ANXIETY" (2020). Open Access Master's Theses. Paper 1868.

https://digitalcommons.uri.edu/theses/1868

This Thesis is brought to you for free and open access by DigitalCommons@URI. It has been accepted for inclusion in Open Access Master's Theses by an authorized administrator of DigitalCommons@URI. For more information, please contact digitalcommons-group@uri.edu. 


\title{
THE ROLE OF SELF-EFFICACY IN THE RELATIONSHIP BETWEEN CHILDHOOD TRAUMA AND ANXIETY
}

\author{
BY \\ ELAINE GREEN
}

\begin{abstract}
A THESIS SUBMITTED IN PARTIAL FULFILLMENT OF THE REQUIREMENTS FOR THE DEGREE OF MASTER OF SCIENCE IN PSYCHOLOGY
\end{abstract}

UNIVERSITY OF RHODE ISLAND 


\section{MASTER OF SCIENCE THESIS}

OF

\section{ELAINE GREEN}

\section{APPROVED:}

Thesis Committee:

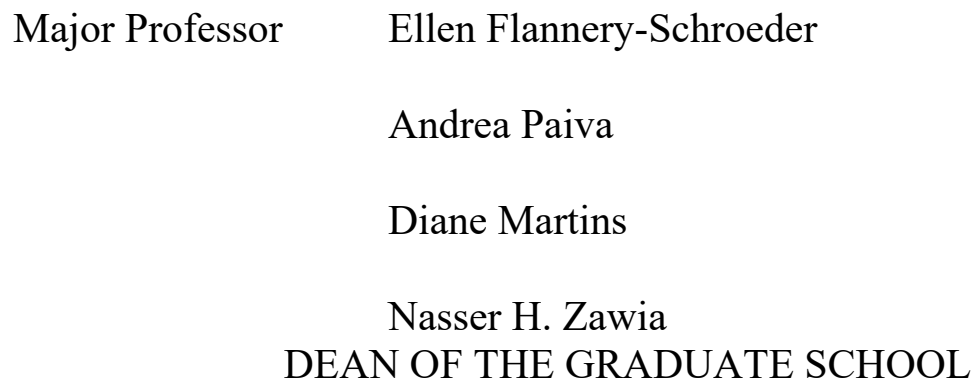

UNIVERSITY OF RHODE ISLAND

2020 


\begin{abstract}
Traumatic childhood experiences (physical abuse and neglect, emotional abuse and neglect, and sexual abuse) have surprisingly high incidence rates and predict to a variety of negative health outcomes, such as anxiety. Although the relationship between childhood trauma and anxiety has been well documented, more research is necessary in order to understand the mechanisms underlying this relationship. The current study hypothesized that academic self-efficacy, the perception that one has the ability to achieve one's desired outcomes in academic endeavors, would mediate the relationship between childhood trauma and anxiety in a sample of college students $(n=204)$. Furthermore, it was hypothesized that gender would moderate the relationship between childhood trauma and anxiety. The current study analyzed emotional abuse (EA), emotional neglect (EN) and physical neglect (PN) separately. Results indicated that although EA, EN, and PN were significant predictors of academic self-efficacy, academic self-efficacy was not a significant predictor of anxiety; therefore, academic self-efficacy did not serve as a mediator for the relationship between childhood trauma and anxiety. Additionally, findings revealed that gender did not moderate the relationship between childhood trauma and anxiety. Limitations of the current study as well as future directions are discussed.
\end{abstract}




\section{ACKNOWLEDGMENTS}

I would like to thank my major professor, Dr. Ellen Flannery-Schroeder, for her continuous support and guidance throughout my time in graduate school. She has provided the data and tools necessary for the completion of this thesis and has always been dedicated to see me succeed. I am utterly grateful for her mentorship and encouragement, and for always prioritizing her students.

I would also like to thank my thesis committee members, Dr. Andrea Paiva and Dr. Diane Martins, for their guidance and feedback throughout this process. I am grateful for their time and commitment to support me throughout this project.

Finally, I would like to thank my family for the endless amounts of support and encouragement they have provided me throughout my life and through graduate

school. Without my parents, Sinthia and Ramon, the completion of this thesis and the pursuit of my academic goals would not have been possible. 


\section{TABLE OF CONTENTS}

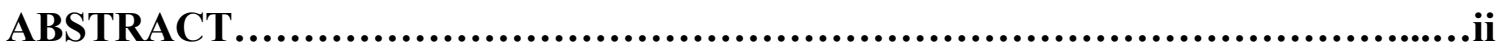

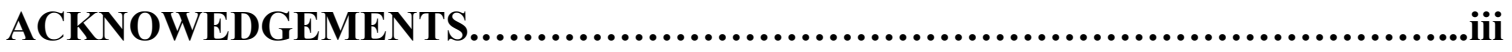

TABLE OF CONTENTS..........................................................

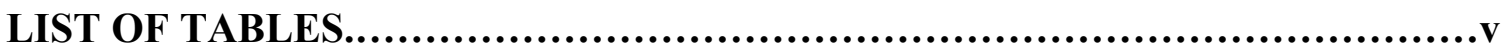

LIST OF FIGURES............................................................vi

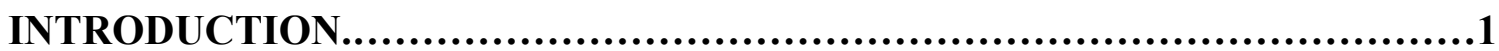

METHOD...........................................................................10

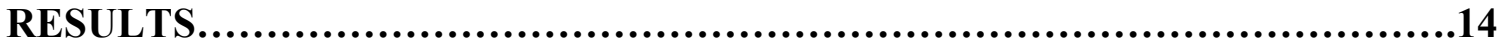

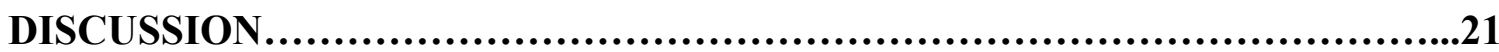

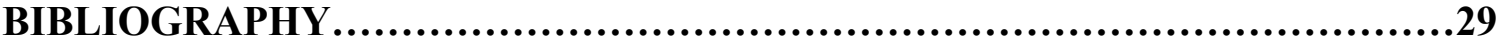




\section{LIST OF TABLES}

Table 1. Demographic Information of Overall Sample..............................11

Table 2. Severity Cut-off Scores for CTQ subscales............................... 12

Table 3. Ranges, Means, and Standard Deviations for Primary Scales in Overall Sample.14

Table 4. Distribution of CTQ Scores.........................................14

Table 5. Distribution of GAD-7 Scores........................................ 15

Table 6. Distribution of SEQ Scores.......................................... 15

Table 7. Correlation Matrix................................................... 16

Table 8. Means and Standard Deviations for Study Variables by Gender................16 


\section{LIST OF FIGURES}

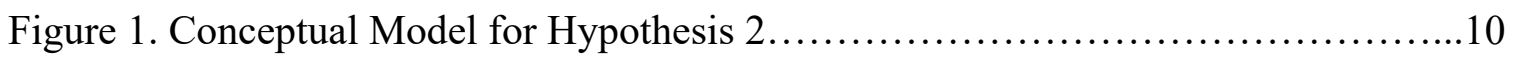

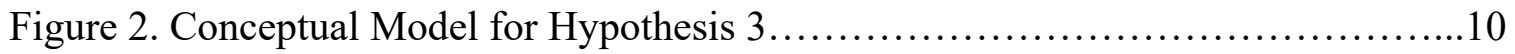

Figure 3. Results of Hierarchical Regression Analyses for the relationships between

Emotional Abuse, Self-efficacy and Anxiety..................................... 18

Figure 4. Results of Hierarchical Regression Analyses for the relationships between

Emotional Neglect, Self-efficacy and Anxiety................................ 19

Figure 5. Results of Hierarchical Regression Analyses for the relationships between

Physical Neglect, Self-efficacy and Anxiety.................................. 19 


\section{Introduction}

\section{Statement of the Problem}

Traumatic childhood experiences (physical abuse and neglect, emotional abuse and neglect, and sexual abuse) have surprisingly high incidence rates and predict to a variety of negative health outcomes (Felitti et al., 1998; Marx, Young, Harvey, 2017; Poole, Dobson \& Pusch, 2017; Sciaraffa, Zeanah \& Zeanah, 2018). Gender differences have been found in prevalence rates of childhood traumatic experiences, types of abuse, and the symptomology related to these experiences (Pruessner et al., 2018; Vahl, Damme, Doreleijers, Vermeiren \& Colins, 2015; Gwadz, Nish, Leonard \& Strauss, 2007). However, most of the research done regarding gender differences has examined clinical populations or disadvantaged groups, and these findings might not be generalizable to the larger population. Anxiety is one of the numerous negative health outcomes associated with childhood trauma (Felitti et al., 1998; Marx et al., 2017; Poole et al., 2017; Sciaraffa et al., 2018). Anxiety disorders are the most prevalent disorders in the United States, impacting millions of people with mild to severe impairment and leading to elevated spending in health services (NIMH, 2017). Research has shown gender disparities in the prevalence rates of anxiety disorders, with women having higher rates of lifetime diagnosis and higher rates of disability (McLean, Asnaani, Litz \& Hofmann, 2011). Although there has been a lot of research conducted regarding anxiety as a sequelae of childhood trauma, more research is needed to understand the numerous factors related to the development of anxiety and the complex relations among these factors. One of these factors is self-efficacy, the belief that one has the ability to achieve desired outcomes (Bandura, 1993; 1997), which has been found to be impacted by childhood trauma 
(Chung, AlQarni, Al Muhairi \& Mitchell, 2017; Bandura, 1997; Benight and Bandura, 2004; Brown, Kouri, Joscelyne, Marmar \& Bryant, 2015; Brown et al., 2016; Diehl \& Prout, 2002; Harter, 1999) and predictive of anxiety disorder symptoms across a number of studies (Muris, 2002; Muris, Meesters, Pierik \& Kock, 2016; Raknes et al., 2017). The relationship between self-efficacy and anxiety is inversely related such that higher selfefficacy is associated with lower levels of anxiety. Furthermore, the research on gender differences regarding self-efficacy has been inconclusive, with some studies showing no gender differences in mean self-efficacy scores (Imam, 2006; Tong \& Song, 2004), while others demonstrating females to have lower general self-efficacy (Ma, Zeng \& Ye, 2015). Still other studies find differences across self-efficacy domains, with females displaying lower social self-efficacy, but higher emotional and academic self-efficacy than their male counterparts (McKay, Dempster, \& Byme, 2014). Notably, much of the research conducted to date has not examined self-efficacy and anxiety in relation to childhood trauma (Guerra, Farkas \& Moncada, 2018). The proposed study aims to (1) evaluate selfefficacy as a possible mediator for the relationship between childhood trauma and anxiety, and (2) evaluate gender as a possible moderator for the relationship between childhood trauma and anxiety.

\section{Review of the Literature}

Childhood Trauma. Traumatic childhood experiences have been found to be highly prevalent and a precursor to a variety of mental health disorders (Felitti et al., 1998; Sciaraffa et al., 2018; Heim \& Nemeroff, 2001). One of the most notable studies assessing the impact of childhood trauma on long-term mental and physical health is the Adverse Childhood Experiences (ACEs) study by Felitti and colleagues (1998). In this 
study, 9,508 adults completed a standardized medical evaluation and answered questions about risk behaviors, health status, and disease. The authors examined seven categories of ACEs (psychological, physical, or sexual abuse; violence against mother; living with household members who were substance abusers, mentally ill or suicidal, or ever imprisoned) and found that traumatic childhood experiences are extremely common in US population (Felitti et al. 1998). Additionally, results demonstrated a "dose-response" relationship between ACEs and health and social problems (Felitti et al. 1998).

Gender Differences in Childhood Trauma. Although traumatic childhood experiences affect both men and women, there is growing evidence to support gender differences among rates and types of childhood trauma (Pruessner et al., 2018; Vahl et al., 2015; Gwadz et al., 2007). For example, in a clinical sample of 210 patients diagnosed with a first episode of psychosis, Pruessner and colleagues (2018) found that males had experienced higher rates of previous physical or emotional neglect whereas females had experienced higher rates of previous emotional abuse. In another study, Vahl and colleagues (2015), in a sample of 341 detained adolescents (46\% male), found that females reported higher rates of maltreatment. They also found that emotional abuse was significantly associated with both internalizing and externalizing disorders for both genders and seemed to have a stronger impact on mental health than other types of abuse. On the other hand, sexual abuse was linked to internalizing symptoms in females and externalizing symptoms in males. Furthermore, Gwadz (2007) and colleagues theorized that gender differences for childhood maltreatment may be specific to certain populations. More specifically, in their sample of 85 youth experiencing homelessness (51\% male), both genders reported experiencing maltreatment at the same rate. Notably, 
a majority of studies examining gender differences in childhood maltreatment have been conducted with clinical or at-risk populations, and few have examined differences within non-clinical samples.

Childhood Trauma and Anxiety. Individual who experienced childhood trauma might be particularly vulnerable to anxiety (Banducci, Lejuez, Dougherty \& MacPherson, 2016; Guerra, Farkas \& Moncada, 2018; Carr, Martins, Stingel, Lemgruber \& Juruena 2013; Poole et al., 2017; Marx et al., 2017; Sciaraffa et al., 2018). Some of the mechanisms that underlie this vulnerability are related to brain development. In early childhood, the brain is rapidly developing and being molded by environmental factors. At this stage, the brain is particularly vulnerable to negative experiences such as emotional, physical and sexual abuse, as well as neglect (Spenrath, Clarke \& Kutcher, 2011; McCain \& Mustard, 1999; Heim \& Nemeroff, 2001). Carr and colleagues (2013) conducted a systematic literature review looking at the effects of early life stress (ELS, traumatic experiences occurring during childhood and adolescence) and their relation to various psychiatric disorders in adulthood. After conducting a meta-analysis of 44 articles, their findings corroborate the relationship between childhood trauma and anxiety that has been found in numerous other studies (e.g., the ACEs study by Felitti and colleagues, 1998).

Due to the strong relationship between childhood trauma and anxiety, many researchers have studied possible mechanisms to explain the relationship. One such mechanism is emotion dysregulation (Huh, Kim, Lee \& Chae, 2017; Poole et al., 2017). Huh and colleagues found that cognitive emotion regulation strategies played a mediating role in the relationship between childhood traumatic experiences and depression and anxiety in a clinical study (Huh et al., 2017). Rumination has also been found to be a 
mediator between childhood trauma and adulthood anxiety (Kim, Jin, Jung, Hahn \& Lee, 2017). Another factor that has been considered in the relationship between childhood trauma and anxiety is distress tolerance (DT), defined as perceived or actual ability to tolerate negative affect and experiences (Banducci et al., 2016). Banducci and colleagues (2016) conducted a 5-year longitudinal study with a community youth sample $(\mathrm{N}=244)$ and found that DT served as a moderator for the relationship of childhood emotional abuse (CEA) and anxiety, so that participants with higher CEA and lower DT had high anxiety levels. Furthermore, resilience, the ability to resume adaptive functioning following stress and/or trauma, has also been studied as a possible moderator for the relationship of childhood trauma and anxiety in later years (Marx et al., 2017; Poole et al., 2017). Resilience has been found to be a protective factor for anxiety in the context of childhood trauma (Marx et al., 2017).

Gender Differences in Anxiety. Females are significantly more likely than males to develop an anxiety disorder throughout the lifespan (McLean et al., 2011; NIMH, 2017). In 2016, prevalence of any anxiety disorder was higher for females (23.4\%) than for males (14.3\%) (NIMH, 2017). McLean and colleagues (2011) examined gender differences a in a large sample of adults $(\mathrm{N}=20,013)$ in the United States using data from the Collaborative Psychiatric Epidemiology Studies (CPES). Results indicated that females with an anxiety disorder are more likely to be diagnosed with a Major Depressive Disorder and Bulimia Nervosa. On the other hand, males with an anxiety disorder are more likely to be diagnosed with a substance use disorder, ADHD, or intermittent explosive disorder (IED) (McLean et al., 2011). Anxious females are also more likely to seek services from emergency rooms, urgent care and doctors than anxious males 
(McLean et al., 2011). Compared to non-anxious females, anxious females missed significantly more days from work over a one month period prior to the study, while anxious males missed about the same days of work than non-anxious males; however, females and males missed approximately the same number of days from work (McLean et al., 2011). Additionally, McLean and colleagues (2011) found no gender differences for the persistence of anxiety disorders or the age of onset.

Childhood Trauma and Self-Efficacy. Although some mechanisms underlying the relationship between childhood trauma and anxiety have been identified, only a portion of the co-variance has been explained, leading to a need for further exploration of the mechanisms explaining this relationship. Self-efficacy, which is independent of actual competence, is the perception that one has the ability to achieve one's desired outcomes (Bandura, 1993; 1997). Self-efficacy has been found to be negatively associated with negative health outcomes post-trauma, such as lower self-efficacy being correlated with higher posttraumatic stress symptoms (Flatten, Walte \& Perlitz, 2008; Luszczynska, Benight \& Cieslak, 2009; Hirschel \& Schulenberg, 2009; Chung et al., 2017; Saigh, Mroueh, Zimmerman \& Fairbank, 1995; Nygaard, Johansen, Siqveland, Hussain \& Heir, 2017). Trauma reduces self-efficacy and in turn elevates posttraumatic stress symptoms (Chung et al., 2017; Bandura, 1997; Benight and Bandura, 2004; Brown et al., 2015; Brown et al., 2016; Diehl \& Prout, 2002; Harter, 1999). Childhood trauma may hinder the development of self-efficacy by increasing negative self-evaluations, negative selfbeliefs and impacting other related cognitive factors (Diehl \& Prout, 2002; Harter, 1999).

Gender Differences in Self-Efficacy. The literature on gender differences regarding self-efficacy displays mixed results. In a sample of 648 Chinese adolescents 
(49\% male), Ma and colleagues (2015) found significant gender differences with males reporting higher self-efficacy. Muris and colleagues (2016) also found gender differences, with females displaying lower self-efficacy and self-esteem and higher levels of anxiety. On the other hand, McKay and colleagues (2014) assessed gender differences in self-efficacy with a sample of 610 adolescents from the United Kingdom and found females to endorse lower social self-efficacy but higher emotional and academic selfefficacy than males. Still other studies have found no gender differences at all. For example, Tong and Song's (2004) study with 266 Chinese college students found no gender difference in an examination of socioeconomic status, general well-being, and general self-efficacy. Similarly, Iman (2006) found no gender differences in self-efficacy scores in a study of 162 undergraduate students in Malaysia.

Self-Efficacy and Anxiety. In social cognitive theory, the perception that one has the ability to assert control over possible "threats" (real or imagined) plays a role in the development of anxiety, so that individuals with low self-efficacy are more likely to develop and maintain anxiety than those with high self-efficacy (Bandura, 1997; Beck, 2011; Raknes et al., 2017). The inverse relationship between self-efficacy and anxiety has been supported by numerous studies. For example, Raknes and colleagues (2017) found self-efficacy to be negatively correlated to anxiety in a sample of 1719 Norwegian adolescents. Participants were categorized either "anxious" or "not anxious" based on composite scores of the Spence Children's Anxiety Scale (SCAS). The researchers found that general self-efficacy was associated with lower levels of anxiety. Muris (2002) also found evidence of this inverse relationship in a sample of nearly 600 adolescents in the Netherlands. In this study, researchers measured state and trait anxiety, as well as general 
self-efficacy and domain-specific self-efficacy such as: social (the perceived capability for peer relationships and assertiveness), academic (the perceived capability to manage one's own learning behavior) and emotional self-efficacy (perceived capability of coping with negative emotions). Muris (2002) not only found that general self-efficacy negatively correlated with trait anxiety and anxiety symptomatology, but also found evidence that domain specific self-efficacy was negatively correlated to specific anxiety disorders (e.g., social self-efficacy was correlated with social anxiety). Similarly, Muris and colleagues (2016) found a particularly strong negative correlation between emotional self-efficacy and anxiety in a sample of 132 non-clinical adolescents. In a regression analysis using self-efficacy as one of the predictors of anxiety, they found that only emotional self-efficacy made a significant contribution. However, academic self-efficacy has been found to be negatively correlated to general stress and anxiety levels (Lavasani, Khezriazar, Amani \& Malahmadi, 2011; Misra \& McKean, 2000), as well as academic related anxiety (i.e., testing anxiety) (Raufelder \& Ringeisen, 2016; Ringeisen, Lichtenfeld, Becker \& Minkley, 2018). Academic self-efficacy is particularly important when working with a sample of undergraduate students due to their high rate of academic stress and negative mental health outcomes (Delene \& Brogowicz, 1990; Kumaraswamy, 2013; Misra \& McKean, 2000).

Childhood Trauma, Anxiety and Self-Efficacy. Although both self-efficacy and childhood trauma have been studied and supporting evidence of correlations between each of these factors and anxiety have been established, few studies have examined the relationships among all three of these factors. Due to self-efficacy's relationship to both childhood trauma and anxiety, it is a construct that deserves further examination as a 
mediator of the relationship between childhood trauma and anxiety. Guerra and colleagues (2018) evaluated the relationships among sexual abuse characteristics (e.g., frequency, level of violence), cognitive and behavioral factors (e.g., self-efficacy) and internalizing symptoms (e.g., anxiety) in a Chilean sample of 106 female adolescents with sexual abuse histories. Results showed that the level of sexual abuse violence was negatively correlated with self-efficacy. Likewise, self-efficacy was negatively correlated with the anxious symptomatology. However, these findings are difficult to generalize due to the small and strictly defined sample who had experienced one type of trauma; therefore, more research is necessary regarding the relationship among childhood trauma, self-efficacy and anxiety (Guerra et al., 2018).

Purpose of Study and Research Questions. There is substantial evidence of the relationship between childhood trauma and anxiety as well as between self-efficacy and anxiety. However, the relationships among all three of these variables have not been sufficiently investigated. The present study aimed to investigate whether academic selfefficacy serves as a mediator of the relationship between traumatic childhood experiences and anxiety and whether gender moderates the relationship between academic selfefficacy and anxiety. Hypotheses are as follows: (1) childhood trauma and anxiety will be positively correlated, (2) academic self-efficacy will mediate this relationship with traumatic childhood experiences being related to high levels of anxiety when selfefficacy is low and lower levels of anxiety when self-efficacy is high (See Figure 1); and (3) gender will moderate the relationship of childhood trauma and anxiety, with females seeing a stronger relationship between childhood trauma and anxiety than males (See Figure 2). In the present study traumatic childhood experiences will be evaluated 
separately by domains: emotional abuse (EA), emotional neglect (EN) and physical neglect (PN).

Figure 1. Conceptual Model for Hypothesis 2

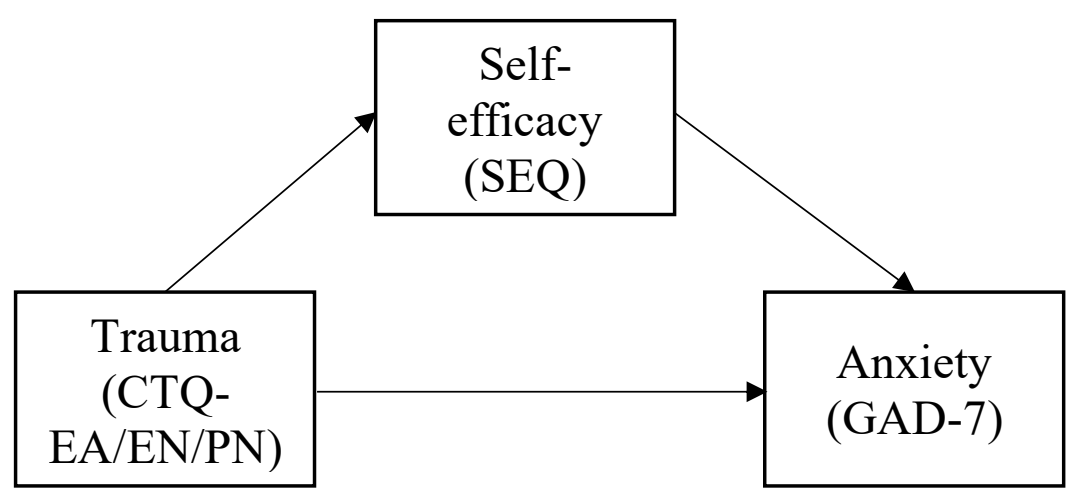

Figure 2. Conceptual Model for Hypothesis 3

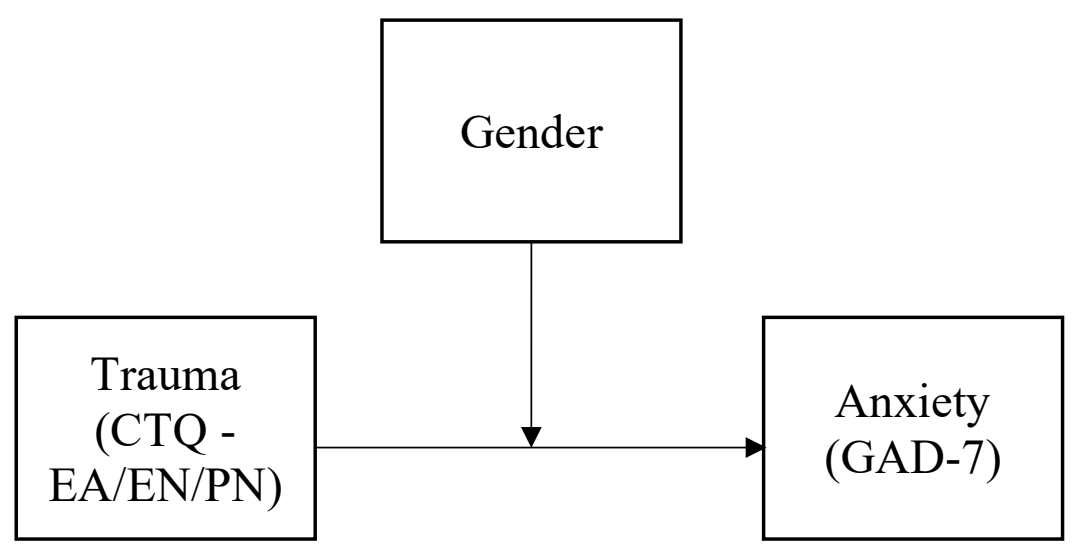

Method

\section{Participants}

Participants $\left(n=204, \mathrm{M}_{\mathrm{age}}=19.5,84.3 \%\right.$ female $)$ were undergraduate students recruited from introductory psychology courses at the University of Rhode Island in the spring of 2018. Additional demographic information is displayed in Table 1 for the 203 participants that reported on all demographic questions. Students were provided with 
extra credit in their college course for their participation, and an alternate extra credit opportunity was available for students choosing not to participate. Participants completed various online questionnaires that were compiled for use in a previous study, including a demographic form and self-report measures of anxiety, childhood trauma and academic self-efficacy. The questionnaires took approximately 30-45 minutes to complete.

\section{Table 1. Demographic Information of Overall Sample}

\begin{tabular}{lrrr}
\hline Variable & $\boldsymbol{N}$ & \multicolumn{2}{c}{$\%$} \\
\hline Ethnicity & & & \\
Hispanic or Latinx: & 25 & $12.3 \%$ \\
Not Hispanic or Latinx & & 178 & $87.7 \%$
\end{tabular}

\section{Gender}

Female

172

84.3

Male

$30 \quad 14.7$

Trans male

Not listed

$\begin{array}{ll}1 & 0.5 \\ 1 & 0.5\end{array}$

\section{Race}

$\begin{array}{lrr}\text { White } & 153 & 76.8 \\ \text { Black } & 18 & 9 \\ \text { Asian } & 6 & 3 \\ \text { American Indian/Alaskan Native } & 2 & 1 \\ \text { Native Hawaiian/Other Pacific Islander } & 1 & 0.5 \\ \text { Multi-racial } & 10 & 5 \\ \text { Other } & 9 & 4.5\end{array}$

\begin{tabular}{lrr} 
Age & & \\
18 & 49 & 24.1 \\
19 & 65 & 32 \\
20 & 49 & 24.1 \\
21 & 25 & 12.3 \\
22 & 7 & 3.4 \\
23 & 3 & 1.5 \\
24 & 5 & 2.5 \\
\hline
\end{tabular}




\section{Measures}

Childhood Trauma Questionnaire (CTQ) is a 28-item self-report measure of childhood traumatic experiences across five clinical scales (physical, sexual, and emotional abuse, and physical and emotional neglect). There are five questions per scale plus three validity questions. Experiences in childhood and adolescence are rated on a 5point, Likert-type scale with response options ranging from Never True to Always True ( 1 = Never True; $2=$ Rarely True; $3=$ Sometimes True; $4=$ Often True; $5=$ Always True). The CTQ has high sensitivity across forms of maltreatments and high reliability and validity (Bernstein et al., 2003). Scores for the CTQ range from 5 to 25. According to the CTQ scoring manual (Bernstein and Fink, 1998), each subscale is separated into four levels of severity, with each subscale having its own cut-offs as displayed in Table 2. Means, standard deviations, and ranges of the current sample for the CTQ are displayed in Table 3.

The current study used the five-item emotional abuse subscale (CTQ-EA), emotional neglect subscale (CTQ-EN), physical neglect subscale (CTQ-PN), physical abuse subscale (CTQ-PA) and sexual abuse subscale (CTQ-SA). All subscales have exhibited a high degree of internal consistency with Cronbach's alpha for the factors ranging from 0.79 to 0.94 (Bernstein et al., 1994).

Table 2. Severity Cut-off Scores for CTQ subscales

\begin{tabular}{lllll}
\hline Scale & $\begin{array}{l}\text { None (or } \\
\text { Minimal) }\end{array}$ & $\begin{array}{l}\text { Low (to } \\
\text { Moderate) }\end{array}$ & $\begin{array}{l}\text { Moderate (to } \\
\text { Severe) }\end{array}$ & $\begin{array}{l}\text { Severe (to } \\
\text { Extreme) }\end{array}$ \\
\hline CTQ-EA & $5-8$ & $9-12$ & $13-15$ & $\geq 16$ \\
CTQ-EN & $5-9$ & $10-14$ & $15-17$ & $\geq 18$ \\
CTQ-PN & $5-7$ & $8-9$ & $10-12$ & $\geq 13$ \\
CTQ-PA & $5-7$ & $8-9$ & $10-12$ & $\geq 13$ \\
CTQ-SA & 5 & $6-7$ & $8-12$ & $\geq 13$ \\
\hline
\end{tabular}


Generalized Anxiety Disorder 7-Item (GAD-7) scale is a seven-item self-report measure of anxiety. Each item is answered on a 4-point Likert-type scale $(0=$ Not at all sure; 1 = Several days; 2 = Over half the days; $3=$ Nearly every day). Internal consistency for the GAD-7 was found to be high $(\alpha=0.92)$, as was test-retest reliability (intraclass correlation $=0.83)$ and procedural validity (intraclass correlation $=0.83)$. The GAD-7 has high sensitivity and specificity as a brief clinical assessment of anxiety (Spitzer, Kroenke, Williams, \& Lowe, 2006). Scores for the GAD-7 range from 0 to 21 with higher scores representing higher levels of anxiety. Scores for the GAD-7 are divided into four severity levels; scores between 0 and 4 are considered "minimal," scores between 5 and 9 are considered "mild," scores between 10 and 14 are considered "moderate," and scores between 15 and 21 are considered "severe." Means, standard deviations, and ranges of the current sample for the GAD-7 are displayed in Table 3.

Self-Efficacy Questionnaire (SEQ) is a thirteen-item self-report measure of selfefficacy with a specific focus on academic self-efficacy. Each item is answered on a 5point Likert-type scale ranging from 1 (Not very like me) to 5 (Very like me). The SelfEfficacy Questionnaire is designed to measure a student's perceived level of proficiency in the two essential components of self-efficacy, which are: 1. belief that ability can grow with effort, and 2. belief in your ability to meet specific goals and/or expectations. The overall self-efficacy questionnaire was found to be highly reliable (13 items; $\alpha=.894$ ). The belief that ability grows with effort subscale consisted of 5 items $(\alpha=.805)$, and the belief in personal ability subscale consisted of 8 items $(\alpha=.841)$ (Gaumer, Soukup, Nooman \& McGum, 2016). Results for the SEQ are displayed on a 100-point scale and 
scores range from 20-100 with higher scores representing higher levels of academic selfefficacy, with the bottom quartile ranging from 20 to 77 and the top quartile ranging from 92 to 100 (Gaumer, Soukup, Nooman \& McGum, 2016). These scores can be interpreted similar to grades (e.g., 70-79 is a C). Means, standard deviations, and ranges of the current sample for the SEQ are displayed in Table 3.

Table 3. Ranges, Means, and Standard Deviations for Primary Scales in Overall Sample.

\begin{tabular}{llllll}
\hline Variable & $\boldsymbol{N}$ & Possible Range & Sample Range & Mean & SD \\
\hline CTQ-EA & 204 & $5-25$ & $5-25$ & 8.27 & 4.3 \\
CTQ-EN & 204 & $5-25$ & $5-25$ & 9.55 & 5.07 \\
CTQ-PN & 204 & $5-25$ & $5-23$ & 7.23 & 3.06 \\
CTQ-PA & 204 & $5-25$ & $5-22$ & 6.20 & 3.07 \\
CTQ-SA & 204 & $5-25$ & $5-25$ & 5.77 & 2.79 \\
GAD-7 & 204 & $0-21$ & $0-21$ & 7.57 & 6.15 \\
SEQ & 204 & $20-100$ & $20-100$ & 79.77 & 14.74 \\
\hline
\end{tabular}

\section{Results}

\section{Preliminary Analysis}

In the current sample, scores ranged from "none" to "severe for CTQ-EA, CTQEN, CTQ-PN, CTQ-PA and CTQ-SA (see Table 4). However, for both CTQ-PA and CTQ-SA, over eighty-five percent of the sample scored "none" (or minimal) trauma. Regarding anxiety, scores for the GAD-7 ranged from "minimal" to "severe" (see Table 5). For the SEQ, scores ranged from 20 to 100 (see Table 6).

Table 4. Distribution of CTQ Scores

\begin{tabular}{lllll}
\hline Scale & $\begin{array}{l}\text { None (or } \\
\text { Minimal) } \\
\text { N (\%) }\end{array}$ & $\begin{array}{l}\text { Low (to } \\
\text { Moderate) } \\
\text { N (\%) }\end{array}$ & $\begin{array}{l}\text { Moderate (to } \\
\text { Severe) } \\
\text { N(\%) }\end{array}$ & $\begin{array}{l}\text { Severe (to } \\
\text { Extreme) } \\
\text { N(\%) }\end{array}$ \\
\hline CTQ-EA & $137(67.10)$ & $37(18.14)$ & $12(5.88)$ & $18(8.82)$
\end{tabular}




\begin{tabular}{lllll} 
CTQ-EN & $129(63.23)$ & $39(19.12)$ & $17(8.33)$ & $19(9.31)$ \\
CTQ-PN & $134(65.69)$ & $31(15.20)$ & $21(10.29)$ & $18(8.82)$ \\
CTQ-PA & $177(86.7)$ & $7(3.5)$ & $8(4)$ & $12(6)$ \\
CTQ-SA & $179(87.7)$ & $5(2.5)$ & $15(7.4)$ & $5(2.5)$ \\
\hline
\end{tabular}

Table 5. Distribution of GAD-7 Scores

\begin{tabular}{lllll}
\hline Scale & $\begin{array}{l}\text { Minimal } \\
\text { N(\%) }\end{array}$ & $\begin{array}{l}\text { Mild } \\
\boldsymbol{N}(\%)\end{array}$ & $\begin{array}{l}\text { Moderate } \\
\boldsymbol{N}(\%)\end{array}$ & $\begin{array}{l}\text { Severe } \\
\boldsymbol{N}(\%)\end{array}$ \\
\hline GAD-7 & $78(38.23)$ & $57(27.94)$ & $41(20.10)$ & $28(13.73)$ \\
\hline
\end{tabular}

Table 6. Distribution of SEQ Scores

\begin{tabular}{|c|c|c|c|c|c|}
\hline Scale & $\begin{array}{l}20-60 \\
N(\%)\end{array}$ & $\begin{array}{l}60-70 \\
N(\%)\end{array}$ & $\begin{array}{l}70-80 \\
N(\%)\end{array}$ & $\begin{array}{l}80-90 \\
N(\%)\end{array}$ & $\begin{array}{l}90-100 \\
N(\%)\end{array}$ \\
\hline SEQ & $13(6.37)$ & $35(17.16)$ & $43(21.08)$ & $57(27.94)$ & $56(27.45)$ \\
\hline
\end{tabular}

Bivariate analysis revealed significant correlations among the variables of interest, except for CTQ-PA and CTQ-SA (see Table 7). CTQ-EA and CTQ-EN were significantly and positively correlated to one another $(\mathrm{r}=.580, p<.01)$. Both variables were also correlated to CTQ-PN: CTQ-EA was positively correlated to CTQ-PN ( $\mathrm{r}=.469$, $p<.01)$, and CTQ-EN exhibited an even stronger positive correlation to CTQ-PN ( $\mathrm{r}=.718$, $p<.01)$. Furthermore, all three variables were significantly and positively correlated to anxiety, such that individuals reporting higher levels of childhood trauma were more likely to report experiencing higher levels of anxiety. CTQ-EA had the strongest correlation to GAD-7 ( $\mathrm{r}=.464, p<.01)$, followed by CTQ-EN ( $\mathrm{r}=.263, p<.01)$, and CTQ$\mathrm{PN}(\mathrm{r}=.217, p<.01)$. Moreover, childhood trauma was significantly and negatively correlated to academic self-efficacy, with individuals reporting higher levels of childhood 
trauma being more likely to report lower levels of self-efficacy. CTQ-EN had the strongest correlation to SEQ $(\mathrm{r}=-.361, p<.01)$, followed by CTQ-PN $(\mathrm{r}=-.323, p<.01)$, and CTQ-EA $(\mathrm{r}=-.230, p<.01)$. Likewise, GAD-7 and SEQ were significantly and positively correlated, such that individuals reporting higher levels of anxiety were more likely to report lower levels of self-efficacy $(\mathrm{r}=-.150, p<.05)$. CTQ-PA was not significantly correlated to SEQ and CTQ-SA was not significantly correlated to SEQ or GAD; therefore, they were not included in further analyses.

Table 7. Correlation Matrix

\begin{tabular}{|c|c|c|c|c|c|c|c|}
\hline & $C T Q \_E A$ & $C T Q \_E N$ & $C T Q \_P N$ & $C T Q \_P A$ & $C T Q \_S A$ & $S E Q$ & GAD-7 \\
\hline CTQ_EA & 1 & $.580^{* *}$ & $.469^{* *}$ & $.576 * *$ & $.177 *$ & $-.230^{* *}$ & $.464^{* *}$ \\
\hline$C T Q \_E N$ & & 1 & $.718^{* *}$ & $.420 * *$ & $.420 * *$ & $-.361^{* *}$ & $.263^{* *}$ \\
\hline$C T Q \_P N$ & & & 1 & $.398^{* *}$ & $.224 * *$ & $-.323^{* *}$ & $.217^{* *}$ \\
\hline$C T Q \_P A$ & & & & 1 & $.300 * *$ & .026 & $.199 * *$ \\
\hline$C T Q \_S A$ & & & & & 1 & .042 & .078 \\
\hline$S E Q$ & & & & & & 1 & $-.150^{*}$ \\
\hline GAD-7 & & & & & & & 1 \\
\hline Note. $\mathrm{N}=2$ & $04, * p<.05$ & $5, * * p<.01$ & & & & & \\
\hline
\end{tabular}

An independent sample t-test was conducted to examine any gender differences in the variables of interest. A t-test revealed significant gender differences for CTQ-EN $(\mathrm{t}(34.496)=-2.606, \mathrm{p}=.013)$ with males reporting higher levels of emotional neglect than their female counterparts. Gender differences were also found for CTQ-PN $(\mathrm{t}(33.141)=$ $2.371, \mathrm{p}=.024)$ with males reporting higher levels of physical neglect than females. Furthermore, there were significant gender differences for GAD-7 $(\mathrm{t}(200)=2.158$, $\mathrm{p}=.032$ ), indicating females reported higher levels of anxiety than males. No significant gender differences were found for CTQ-EA or SEQ. 
Table 8. Means and Standard Deviations for Study Variables by Gender

\begin{tabular}{lllllll}
\hline Variable & Females & \multicolumn{5}{c}{ Males } \\
& Mean & SD & Level & Mean & SD & Level \\
CTQ_EA & 8.20 & 4.25 & "None" & 8.98 & 4.52 & "None" \\
$C T Q \_E N$ & 8.98 & 4.55 & "None" & 12.10 & 6.28 & Low \\
$C T Q \_P N$ & 6.90 & 2.68 & "None" & 8.80 & 4.24 & Low \\
$S E Q$ & 80.55 & 14.06 & B & 76.51 & 17.80 & C \\
$G A D-7$ & 7.94 & 6.07 & "Mild" & 5.33 & 6.22 & "Mild"
\end{tabular}

Note. $\mathrm{N}=202$ ( 2 participants were excluded due to not identifying as male or female)

\section{Mediation Analysis}

Regression analyses were conducted in order to examine the hypothesis that selfefficacy mediates the relationship between emotional abuse and anxiety. In step 1, the regression of emotional abuse on anxiety was significant, $\beta=.65, p<.001$. In step 2 , of the mediation model, the regression of emotional abuse on self-efficacy was also significant, $\beta=-.83, p<.001$. However, in Step 3 of the model, the regression of self-efficacy on anxiety was not significant. Thus, the mediation model was not significant, and selfefficacy did not mediate the relationship between emotional abuse and anxiety. These regressions are depicted in Figure 3.

Regression analyses were also conducted in order to examine the hypothesis that self-efficacy mediates the relationship between emotional neglect and anxiety. In step 1, the regression of emotional neglect on anxiety was significant, $\beta=.33, p<.001$. Step 2 demonstrated that the regression of emotional neglect on self-efficacy was also significant, $\beta=-1.20, p<.001$. Nevertheless, in step 3 , the regression of self-efficacy on anxiety was not significant. Thus, the mediation model was not significant, and self- 
efficacy did not mediate the relationship between emotional neglect and anxiety. These regressions are depicted in Figure 4.

Finally, regression analyses were conducted in order to examine the hypothesis that self-efficacy mediates the relationship between physical neglect and anxiety. In step 1 of the mediation model, the regression of physical neglect on anxiety was significant in step $3, \beta=.42, p<.01$. Step 2 showed that the regression of physical neglect on selfefficacy was also significant, $\beta=-1.50, p<.001$. However, in step 3 , the regression of selfefficacy on anxiety was not significant. Thus, the mediation model was not significant, and self-efficacy did not mediate then relationship between physical neglect and anxiety. These regressions are depicted in Figure 5.

Figure 3. Results of Hierarchical Regression Analyses for the relationships between Emotional Abuse, Self-efficacy and Anxiety

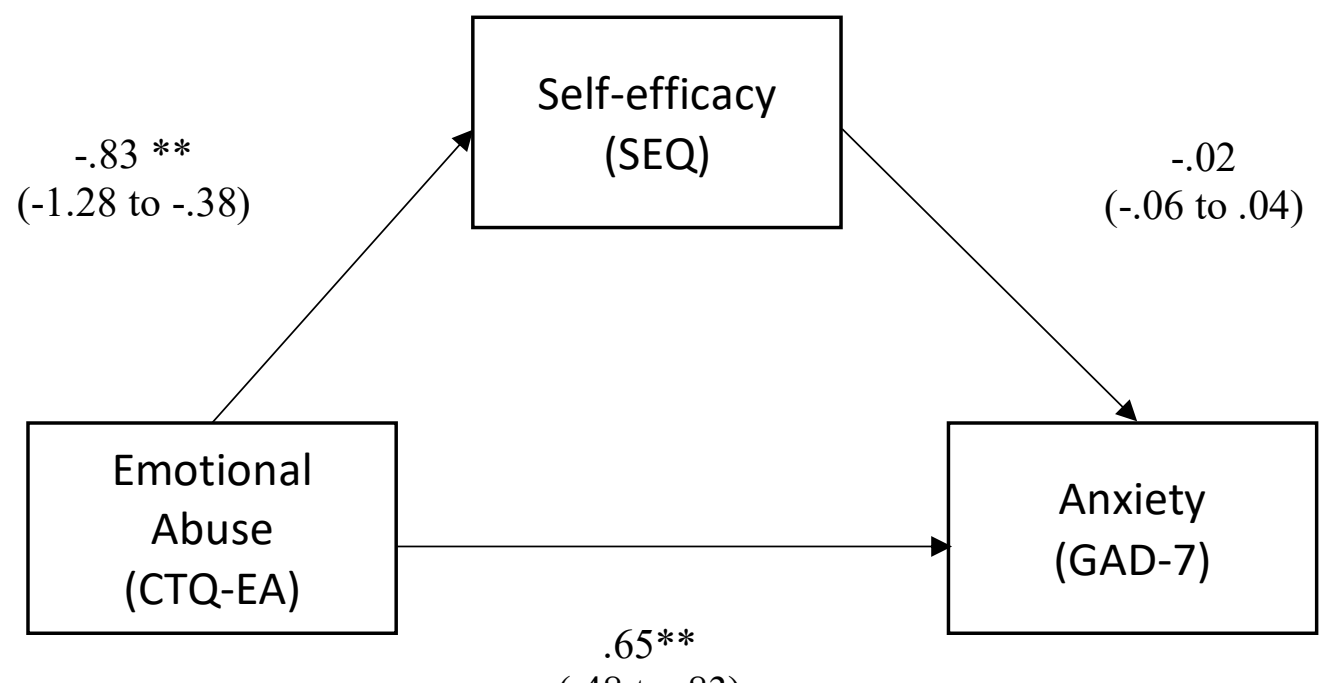

(.48 to .83$)$

Note. ${ }^{*} p<.05,{ }^{* *} p<.01$ 
Figure 4. Results of Hierarchical Regression Analyses for the relationships between Emotional Neglect, Self-efficacy and Anxiety

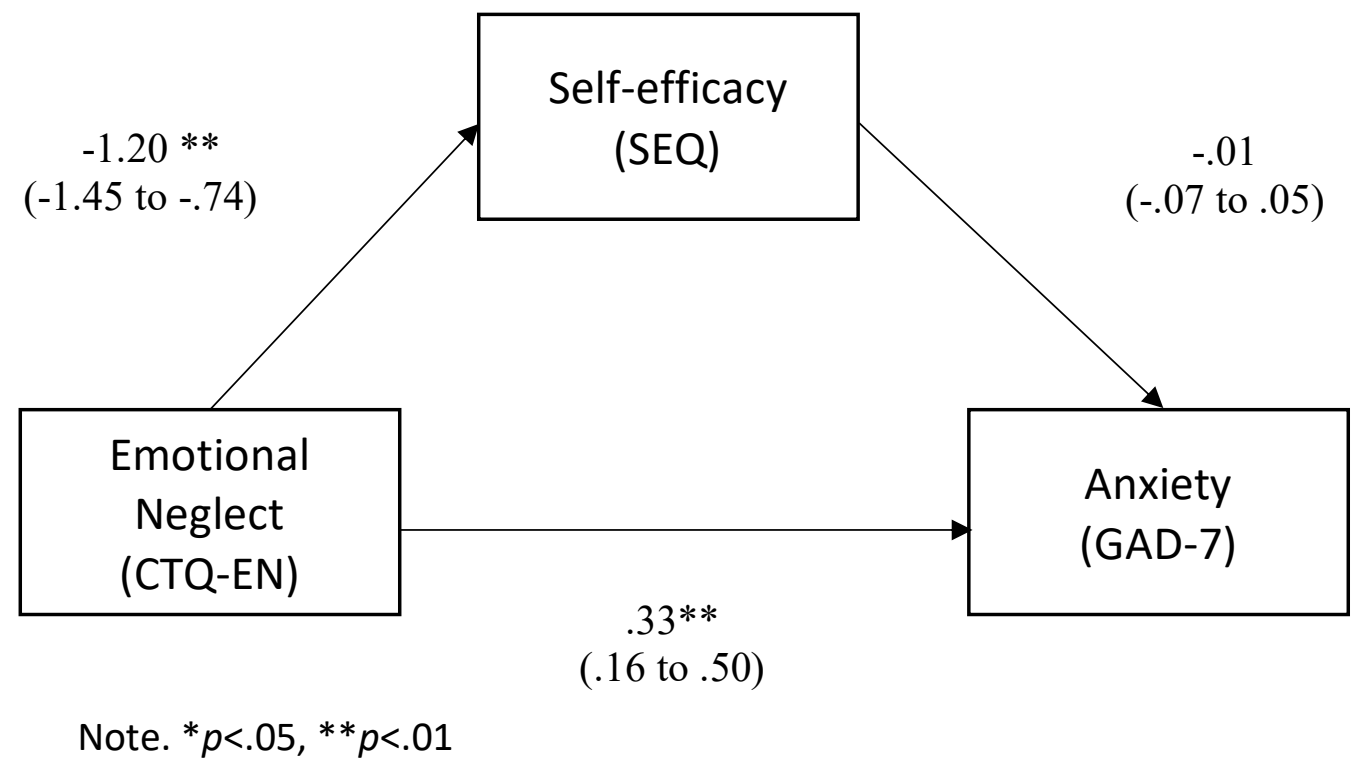

Figure 5. Results of Hierarchical Regression Analyses for the relationships between Physical Neglect, Self-efficacy and Anxiety

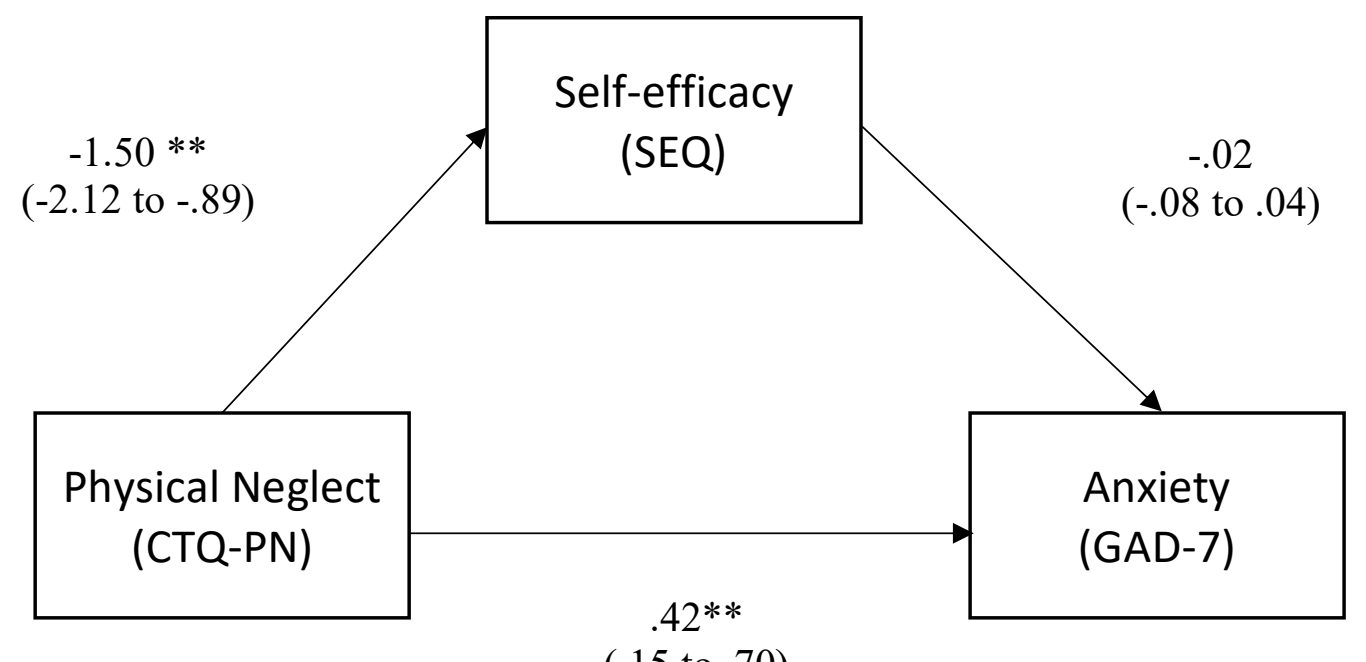

(.15 to .70$)$

Note. ${ }^{*} p<.05,{ }^{* *} p<.01$ 


\section{Moderation Analyses}

Regression analyses were conducted in order to examine if gender moderates the relationship between emotional abuse and anxiety. In step 1 of the moderation model, results indicated that emotional abuse (IV) and gender (M) accounted for approximately $22 \%$ of the variance in anxiety $(\mathrm{DV})\left(R^{2}=.22, F(3,226)=20.98, p<.001\right)$. Emotional abuse was a significant predictor of anxiety $(b=.65,95 \% \mathrm{CI}[.48, .81], \mathrm{t}=7.77, \mathrm{p}<$ .001 ), but gender was not. In step 2, the interaction term between emotional abuse and gender was examined. Results indicated that the interaction was not significant $(b=-.03$, $95 \% \mathrm{CI}[-33, .26], \mathrm{t}=-.21, \mathrm{p}=.83)$. Thus, gender did not have a moderating effect on the relationship between emotional abuse and anxiety.

Regression analyses were also conducted in order to examine if gender moderates the relationship between emotional neglect and anxiety. In step 1 of the moderation model, results indicated that emotional neglect (IV) and gender (M) accounted for approximately $12 \%$ of the variance in anxiety $(\mathrm{DV})\left(R^{2}=.12, F(3,231)=10.25, p<.001\right)$. Emotional neglect was a significant predictor of anxiety $(b=.41,95 \% \mathrm{CI}[.26, .56], \mathrm{t}=$ $5.29, \mathrm{p}<.001)$, as was gender $(\mathrm{b}=-2.25,95 \%$ CI $[-4.29,-2.11], \mathrm{t}=-2.17, \mathrm{p}<.05)$. In step 2, the interaction term between emotional neglect and gender was examined. Results indicated that the interaction was not significant $(b=-.01,95 \%$ CI $[-19, .18], \mathrm{t}=-.05$, $\mathrm{p}=.95$ ). Thus, gender did not have a moderating effect on the relationship between emotional neglect and anxiety.

Finally, regression analyses were conducted in order to examine if gender moderates the relationship between physical neglect and anxiety. In step 1 of the 
moderation model, results indicated that physical neglect (IV) and gender (M) accounted for approximately $8 \%$ of the variance in anxiety (DV) $\left(R^{2}=.08, F(3,227)=6.89\right.$, $p<.001)$. Physical neglect was a significant predictor of anxiety $(\mathrm{b}=.54,95 \% \mathrm{CI}[.28$, $.79], t=4.16, p<.001)$, but gender was not. In step 2 , the interaction term between physical neglect and gender was examined. Results indicated that the interaction was not significant $(b=-.22,95 \%$ CI $[-64, .20], t=-1.03, p=.30)$. Thus, gender did not have a moderating effect on the relationship between physical neglect and anxiety.

\section{Discussion}

The current study was aimed at expanding the literature regarding the relationship between childhood trauma and anxiety. As hypothesized, findings indicated significant positive correlations between childhood trauma and anxiety, with one exception. Positive correlations were found for emotional abuse, emotional neglect, physical neglect and physical abuse, but not for sexual abuse. The lack of a relationship between sexual abuse and anxiety may be related to the small portion of the sample (12\%) that endorsed sexual abuse, which is roughly comparable to the prevalence rate of the general population $(9 \%)$ (U.S. Department of Health \& Human Services, 2019). When combining both physical and emotional neglect, the prevalence rate of the current sample $(71 \%)$ is also comparable to that of the general population (75\%); as is also the physical abuse rates in the current sample (13\% in the present study compared to $18 \%$ for the general population) (U.S. Department of Health \& Human Services, 2019). The U.S. Department of Health and Human Services does not report a prevalence of emotional abuse; yet, it reports a $6 \%$ prevalence rate of psychological maltreatment (2019). These correlations between childhood trauma and anxiety are in line with previous findings. 
Significant negative correlations were found between academic self-efficacy and emotional abuse, emotional neglect, and physical neglect; however, physical abuse and sexual abuse were not significantly correlated to self-efficacy. The lack of significant associations between sexual and physical abuse may be related to the small portion of the sample that endorsed these types of abuse, as noted above. These findings support previous research indicating that childhood trauma may hinder the development of selfefficacy (Diehl \& Prout, 2002; Harter, 1999). Furthermore, academic self-efficacy and anxiety were also found to be significantly negatively correlated, which is in agreement with previous research (Lavasani, Khezriazar, Amani \& Malahmadi, 2011; Misra \& McKean, 2000).

Given previous research regarding the relationships among these variables, the second hypothesis proposed that academic self-efficacy would mediate the relationship between childhood trauma and anxiety. This study, to our knowledge, was the first to explore self-efficacy as a mediator of this relationship. Findings revealed that although emotional and physical abuse and physical neglect were significant predictors of academic self-efficacy, academic self-efficacy was not a significant predictor of anxiety; therefore, academic self-efficacy did not serve as a mediator for the relationship between childhood trauma and anxiety. These findings support previous research indicating that childhood trauma leads to lower self-efficacy; however, these findings do not support the role of academic self-efficacy in the development and maintenance of anxiety. These unexpected findings may be related to the measure used for academic self-efficacy, which is limited in its assessment of negative self-beliefs and negative self-evaluations that may be associated with higher levels of general anxiety. Previous research has found 
that emotional self-efficacy was a significant contributor to anxiety (Muris, 2016).

Furthermore, there is evidence that academic self-efficacy may be associated with specific testing and academic-related anxiety (Muris, 2002). The present study utilized a measure for generalized anxiety, which may not have adequately captured academicrelated anxiety. Therefore, future research should explore the role of different types of self-efficacy in the relationship between trauma and different types of anxiety.

The present study also hypothesized that gender would moderate the relationship between childhood trauma and anxiety. Based on previous research, gender differences in childhood trauma were expected, such that females endorsed higher levels of trauma than males (Vahl et al, 2015). Findings revealed gender differences only among emotional neglect and physical neglect, with males endorsing higher levels of neglect compared to females. Contrary to previous research, however, there were no significant gender differences in emotional abuse. The findings of higher levels of neglect endorsed by males (vs. females) supports previous findings from studies conducted with patients experiencing psychosis (Pruessner et al., 2018). These findings expand the literature, demonstrating that males may experience higher levels of physical and emotional neglect in the general population, although this neglect does not necessarily translate to higher levels of anxiety. Future research should explore how higher levels of physical and emotional neglect may impact male's mental health and identify potential factors which may serve to mediate the relationship between these forms of neglect and anxiety in males. Moreover, there were also gender differences found in levels of anxiety, with females reporting higher levels of anxiety than males. This finding supports the literature regarding anxiety disorder prevalence. Although these gender differences in anxiety were 
significant, gender did not moderate the relationship between trauma and anxiety. These findings may have been impacted by an unequal sample ( $84 \%$ female). Previous findings indicate that emotional abuse is a more robust predictor of anxiety and that females often endorse higher levels of emotional abuse (Vahl et al., 2015). Nevertheless, we did not find gender differences in emotional abuse in the present study, and accordingly, did not

find moderation by gender. Regarding gender differences in self-efficacy, results revealed no significant findings. This result contributes to the current and conflicting literature regarding gender differences in self-efficacy, in which some studies find females to endorse higher academic self-efficacy than males (McKay et al., 2014), while other studies find the inverse (Ma et al., 2015, Muris et al., 2016). Further research should consider exploring gender differences in childhood trauma, self-efficacy, and anxiety with larger and more diverse samples in order to attain more conclusive and generalizable results.

\section{Limitations}

Although the current study has contributed to the literature regarding childhood trauma, anxiety and self-efficacy, there are several important limitations to consider. First, the current sample was very homogeneous ( $84 \%$ female, $77 \%$ White, $88 \%$ NonHispanic). All participants were recruited from the same north-eastern university in the United States through undergraduate psychology courses. This may have impacted the ability of finding significant differences across gender and may have led to the lack of variability in levels of trauma (e.g., $85 \%$ endorsed "none" to "low" emotional abuse). There was low endorsement of clinical levels of childhood trauma (moderate to severe) across trauma types, with physical neglect having the highest rate (19\% endorsed 
moderate to severe). In addition, this homogeneity makes it difficult to generalize the results to a wider population of individuals. Future research should employ random sampling and should strive to have equal size groups by gender. Moreover, future research should explore the relationships between trauma, self-efficacy and anxiety in samples with higher rates of clinical levels of childhood trauma. These limitations may be addressed by using nationally representative normative samples, as well as clinical samples, in order to enhance generalizability.

Furthermore, there are also limitations related to the measures used. The childhood trauma measure used in the current study, the CTQ, is a self-reported, retrospective measure of childhood traumatic experiences. Even though this measure has shown validity and reliability in samples such as college undergraduates, responses are vulnerable to biases or distorted memories caused by the passage of time. The retrospective nature of this measure may also be related to the lower endorsement of traumatic experiences. Future studies should consider longitudinal models to account for this limitation or use interviews and reports by health professionals in order to have a more accurate report of trauma.

Regarding anxiety, the GAD-7 is also a self-reported measure, which makes it vulnerable to response bias. Although this measure is often used by researchers to measure anxiety at large due to the various symptoms that are found across anxiety disorders, the GAD-7 is very brief and specific to Generalized Anxiety Disorder, and, therefore, may not provide a complete picture of the anxiety experienced by our sample. Future research should assess various types of anxiety or use a broader measure. 
Based on previous research indicating the impact academic stress and selfefficacy has on undergraduates' mental health, the current study looked specifically at academic self-efficacy. Yet, the SEQ is a self-reported measure and, thus, scores may be susceptible to social desirability bias. Additionally, other forms of self-efficacy, including emotional, social, or general self-efficacy, may also be related to childhood trauma and anxiety. Therefore, it is important for future research to measure self-efficacy in different domains and explore which specific types of self-efficacy, if any, mediate the relationship between childhood trauma and anxiety.

\section{Future Directions}

The current study explored several important questions regarding the relationship of childhood trauma, self-efficacy, and anxiety and contributed to the literature regarding gender differences in childhood trauma. The results of the present study indicated that childhood trauma (EA, EN, PN) was a significant predictor of academic self-efficacy, but academic self-efficacy was not a significant predictor of anxiety; thus, academic selfefficacy was not a mediator of childhood trauma and anxiety. These findings indicate a need for interventions targeting survivors of childhood trauma to incorporate strategies that would increase self-efficacy (both general and academic) in this population. Furthermore, results revealed gender differences among emotional neglect and physical neglect, with males endorsing higher levels of neglect compared to females. However, gender was not found to be a moderator of the relationship between childhood trauma and anxiety.

Although the present study has contributed to the literature, there are numerous ways to improve and build upon the current research. Future research should utilize a 
larger and more heterogeneous sample, with a focus on exploring the full range of gender identities and representative ethnic and racial groups. Future researchers should consider conducting mixed-method studies and combining self-reported data with psychodiagnostics interviews and health history reports to best assess for childhood trauma, self-efficacy, and anxiety. This approach may lessen the effect of social desirability biases and may lead to more accurate measures of these constructs. Future research may also benefit from employing measures for various domains of self-efficacy, which may be more closely related to the development and maintenance of anxiety, such as emotional, social, and coping self-efficacy. It may also be beneficial for future studies to evaluate other specific types of anxiety disorders and explore any differences that may arise in trauma and self-efficacy across disorders. Moreover, longitudinal studies may be useful in looking at childhood trauma as a predictor of self-efficacy and, in turn, anxiety. Other possible mediators of the relationship between childhood trauma and anxiety (e.g., self-esteem) should also be explored.

Due to the current findings indicating males reporting higher levels of childhood emotional and physical neglect, it is imperative for future research to explore risk and protective factors of childhood neglect in males, such as differences in socialization and the impact of gender roles. These findings also indicate the need for preventive interventions targeting child neglect in young males and a need for interventions tailored to men who have experienced emotional and/or physical neglect. Furthermore, the literature on gender differences in academic self-efficacy is scarce and the results are mixed. Therefore, future research should investigate gender differences in a more representative sample. 


\section{Conclusion}

In sum, findings indicate that there are significant associations among trauma, academic self-efficacy, and anxiety; however, academic self-efficacy did not mediate the relationship between childhood trauma and anxiety. Future research should explore different types of self-efficacy that may be more significantly associated with anxiety. Furthermore, gender did not moderate the relationship between trauma and anxiety, although there were some differences found in trauma and anxiety across gender. Specifically, males endorsed higher levels of physical and emotional neglect, while females endorsed higher levels of anxiety. Current findings did not support previous findings of females endorsing higher emotional abuse. Thus, gender differences in risk and protective factors of trauma and anxiety should be further examined. A replication and extension of the current study could inform treatment for children who have experienced trauma, as well as preventive interventions for anxiety. 


\section{Bibliography}

Banducci, A. N., Lejuez, C. W., Dougherty, L. R., \& MacPherson, L. (2017). A prospective examination of the relations between emotional abuse and anxiety: Moderation by distress tolerance. Prevention Science, 18(1), 20-30.

Bandura, A. (1993). Perceived self-efficacy in cognitive development and functioning. Educational Psychologist, 28(2), 117-148.

Bandura, A. (1997). Self-efficacy: the exercise of control. New York: Freeman

Beck, J. (2011). Cognitive behavior therapy: Basics and beyond (2nd ed.). New York, NY: The Guilford Press

Benight, C.C., Bandura, A., (2004). Social cognitive theory of posttraumatic recovery: the role of perceived self-efficacy. Behav. Res. Ther. 42, 1129e1148.

Bernstein, D. P., Fink, L., Handelsman, L., Foote, J., Lovejoy, M., Wenzel, K., ... \& Ruggiero, J. (1994). Initial reliability and validity of a new retrospective measure of child abuse and neglect. The American journal of psychiatry.

Bernstein, D. P., \& Fink, L. (1998). Childhood Trauma Questionnaire: A retrospective self-report manual San Antonio, TX: The Psychological Corporation.

Bernstein, D. P., Stein, J. A., Newcomb, M. D., Walker, E., Pogge, D., Ahluvalia, T., ... Zule, W. (2003). Development and validation of a brief screening version of the Childhood Trauma Questionnaire. Child Abuse \& Neglect, 27(2), 169190. 
Brown, A.D., Kouri, N.A., Joscelyne, A., Marmar, C.R., Bryant, R.A., (2015). Experimentally examining the role of self-identity in posttraumatic stress disorder. In: Watson, Lynn A., Bernsten, Dorthe (Eds.), Clinical Perspectives on Autobiographical Memory (Pp 316e334). Cambridge University Press; US, New York, NY, US, pp. $316 \mathrm{e} 334$ xiv, 387 pp.

Brown, A.D., Kouri, N.A., Rahman, N., Joscelyne, A., Bryant, R.A., Marmar, C.R., (2016). Enhancing self-efficacy improves episodic future thinking and social decision making in combat veterans with posttraumatic stress disorder. Psychiatry Res. 242, 19e25.

Carr, C. P., Martins, C. M. S., Stingel, A. M., Lemgruber, V. B., \& Juruena, M. F. (2013). The role of early life stress in adult psychiatric disorders: A systematic review according to childhood trauma subtypes. Journal of Nervous and Mental Disease, 201(12), 1007-1020.

Chung, M. C., AlQarni, N., Al Muhairi, S., \& Mitchell, B. (2017). The relationship between trauma centrality, self-efficacy, posttraumatic stress and psychiatric co-morbidity among Syrian refugees: Is gender a moderator? Journal of Psychiatric Research, 94, 107-115.

Delene, L. M., \& Brogowicz, A. A. (1990). Student healthcare needs, attitudes, and behavior: Marketing implications for college health centers. Journal of American College Health, 38(4), 157-164.

Diehl, A. S., \& Prout, M. F. (2002). Effects of posttraumatic stress disorder and child sexual abuse on self-efficacy development. American Journal of Orthopsychiatry, 72(2), 262-265. 
Felitti, V. J., Anda, R. F., Nordenberg, D., Williamson, D. F., Spitz, A. M., Edwards, V., ... Marks, J. S. (1998). Relationship of childhood abuse and household dysfunction to many of the leading causes of death in adults: The Adverse Childhood Experiences (ACE) Study. American Journal of Preventive Medicine, 14(4), 245-258.

Flatten, G., Wälte, D., \& Perlitz, V. (2008). Self-efficacy in acutely traumatized patients and the risk of developing a posttraumatic stress syndrome. GMS Psycho-Social-Medicine, 5.

Gaumer Erickson, A.S., Soukup, J.H., Nooman, P.M., \& McGum, L. (2016). SelfEfficacy Questionnaire. Lawrence, KS: University of Kansas, Center of Research and Learning.

Guerra, C., Farkas, C., \& Moncada, L. (2018). Depression, anxiety and PTSD in sexually abused adolescents: Association with self-efficacy, coping and family support. Child Abuse \& Neglect, 76, 310-320.

Gwadz, M. V., Nish, D., Leonard, N. R., \& Strauss, S. M. (2007). Gender differences in traumatic events and rates of post-traumatic stress disorder among homeless youth. Journal of Adolescence, 30(1), 117-129.

Harter. S. (1999). The construction of the self. New York: Guilford Press.

Heim, C., \& Nemeroff, C. B. (2001). The role of childhood trauma in the neurobiology of mood and anxiety disorders: Preclinical and clinical studies. Biological Psychiatry, 49(12), 1023-1039.

Huh, H. J., Kim, K. H., Lee, H.-K., \& Chae, J.-H. (2017). The relationship between childhood trauma and the severity of adulthood depression and anxiety 
symptoms in a clinical sample: The mediating role of cognitive emotion regulation strategies. Journal of Affective Disorders, 213, 44-50.

Imam, S. (2006). General self-efficacy among undergraduate university students in Malaysia. Pakistan Journal of Social and Clinical Psychology, 4(1), 39-52.

Kim, J. S., Jin, M. J., Jung, W., Hahn, S. W., \& Lee, S.-H. (2017). Rumination as a mediator between childhood trauma and adulthood depression/anxiety in nonclinical participants. Frontiers in Psychology, 8.

Kumaraswamy, N. (2013). Academic stress, anxiety and depression among college students: A brief review. International review of social sciences and humanities, 5(1), 135-143.

Lavasani, M. G., Khezriazar, H., Amani, J., \& Malahmadi, E. (2011). The role of academic self-efficacy and achievement goals in level of stress, anxiety, and depression of university students. Journal of Psychology, 14(4), 417-432.

Luszczynska, A., Benight, C. C., \& Cieslak, R. (2009). Self-efficacy and healthrelated outcomes of collective trauma: A systematic review. European Psychologist, 14(1), 51-62.

Ma, Z. W., Zeng, W. N., \& Ye, K. Y. (2015). Gender differences in Chinese adolescents' subjective well-being: the mediating role of self-efficacy. Psychological reports, 116(1), 311-321.

Marx, M., Young, S. Y., Harvey, J., Rosenstein, D., \& Seedat, S. (2017). An examination of differences in psychological resilience between social anxiety disorder and posttraumatic stress disorder in the context of early childhood trauma. Frontiers in Psychology, 8. 
McCain, M. N., \& Mustard, J. F. (1999). Reversing the real brain drain: Early years study. Council for Early Child Development.

McKay, M. T., Dempster, M., \& Byrne, D. G. (2014). An examination of the relationship between self-efficacy and stress in adolescents: the role of gender and self-esteem. Journal of youth studies, 17(9), 1131-1151.

McLean, C. P., Asnaani, A., Litz, B. T., \& Hofmann, S. G. (2011). Gender differences in anxiety disorders: prevalence, course of illness, comorbidity and burden of illness. Journal of psychiatric research, 45(8), 1027-1035.

Misra, R., \& McKean, M. (2000). College students' academic stress and its relation to their anxiety, time management, and leisure satisfaction. American journal of Health studies, 16(1), 41.

Mossman, S. A., Luft, M. J., Schroeder, H. K., Varney, S. T., Fleck, D. E., Barzman, D. H., ... Strawn, J. R. (2017). The Generalized Anxiety Disorder 7-item scale in adolescents with generalized anxiety disorder: Signal detection and validation. Annals of Clinical Psychiatry, 29(4), 227-234.

Muris, P. (2002). Relationships between self-efficacy and symptoms of anxiety disorders and depression in a normal adolescent sample. Personality and Individual Differences, 32(2), 337-348.

Muris, P., Meesters, C., Pierik, A., \& de Kock, B. (2016). Good for the self: Selfcompassion and other self-related constructs in relation to symptoms of anxiety and depression in non-clinical youths. Journal of Child and Family Studies, 25(2), 607-617. 
NIMH (2017). Any Anxiety Disorder. Retrieved from https://www.nimh.nih.gov/health/statistics/any-anxiety-disorder.shtml. Accessed on November 16 $6^{\text {th }}, 2019$.

Nygaard, E., Johansen, V. A., Siqveland, J., Hussain, A., \& Heir, T. (2017). Longitudinal relationship between self-efficacy and posttraumatic stress symptoms 8 years after a violent assault: An autoregressive cross-lagged model. Frontiers in Psychology, 8.

Poole, J. C., Dobson, K. S., \& Pusch, D. (2017). Anxiety among adults with a history of childhood adversity: Psychological resilience moderates the indirect effect of emotion dysregulation. Journal of Affective Disorders, 217, 144-152.

Pruessner, M., King, S., Vracotas, N., Abadi, S., Iyer, S., Malla, A. K., ... \& Joober, R. (2019). Gender differences in childhood trauma in first episode psychosis: Association with symptom severity over two years. Schizophrenia research, $205,30-37$.

Raknes, S., Pallesen, S., Bjaastad, J. F., Wergeland, G. J., Hoffart, A., Dyregrov, K., ... Haugland, B. S. M. (2017). Negative life events, social support, and selfefficacy in anxious adolescents. Psychological Reports, 120(4), 609-626.

Raufelder, D., \& Ringeisen, T. (2016). Self-perceived competence and test anxiety: The role of academic self-concept and self-efficacy. Journal of Individual Differences, 37(3), 159-167.

Ringeisen, T., Lichtenfeld, S., Becker, S., \& Minkley, N. (2018). Stress experience and performance during an oral exam: The role of self-efficacy, threat 
appraisals, anxiety, and cortisol. Anxiety, Stress \& Coping: An International Journal. https://doi-org.uri.idm.oclc.org/10.1080/10615806.2018.1528528

Saigh, P. A., Mroueh, M., Zimmerman, B. J., \& Fairbank, J. A. (1995). Self-efficacy expectations among traumatized adolescents. Behaviour Research and Therapy, 33(6), 701-704.

Sciaraffa, M. A., Zeanah, P. D., \& Zeanah, C. H. (2018). Understanding and promoting resilience in the context of adverse childhood experiences. Early Childhood Education Journal, 46(3), 343-353.

Spenrath, M. A., Clarke, M. E., \& Kutcher, S. (2011). The science of brain and biological development: Implications for mental health research, practice and policy. Journal of the Canadian Academy of Child and Adolescent Psychiatry / Journal de l'Académie Canadienne de Psychiatrie de l'enfant et de l'adolescent, 20(4), 298-305.

Spitzer, R. L., Kroenke, K., Williams, J. B., \& Lowe, B. (2006). A brief measure for assessing generalized anxiety disorder. Achieves of Internal Medicine, 166, 1092-1097.

Tong, Y., \& Song, S. (2004). A study on general self-efficacy and subjective wellbeing of low SES-college students in a Chinese university. College Student Journal, 38(4), 637-643.

U.S. Department of Health \& Human Services, Administration for Children and Families, Administration on Children, Youth and Families, Children's Bureau. (2019). Child Maltreatment 2017. 
Vahl, P., Van Damme, L., Doreleijers, T., Vermeiren, R., \& Colins, O. (2016). The unique relation of childhood emotional maltreatment with mental health problems among detained male and female adolescents. Child abuse \& neglect, 62, 142-150. 